\title{
LA PERSONA JURÍDICA EN LAS PROPUESTAS DE LOS OBISPOS CHILENOS A LA CODIFICACIÓN DEL DERECHO CANÓNICO DE 1917
}

\author{
CARlos SALinas ARANEDA*
}

RESUMEN: La redacción del primer Código de Derecho Canónico que tuvo la Iglesia latina fue ordenada por el papa san Pio X en 1904. La tarea codificadora, empero, no fue obra de un grupo cerrado de expertos, sino que tuvo en cuenta el parecer del episcopado, el que fue consultado en dos momentos diferentes; en ambos fueron consultados los obispos chilenos. En este trabajo se estudia, a partir de la documentación guardada en el Archivo Secreto Vaticano, el aporte de los obispos chilenos en la primera consulta, realizada en 1904 , en lo referido a las personas jurídicas ${ }^{* *}$.

PALABRAS CLAVE: Codificación canónica - Código de Derecho Canónico de 1917 - obispos chilenos - postulata episcoporum - persona jurídica - persona moral.

\section{THE JURISTIC PERSON IN THE PROPOSALS OF CHILEAN BISHOPS TO THE CANON LAW CODING OF 1917}

ABSTRACT: The writing of the first Code of Canon Law by the Latin Church was ordered by Pope Saint Pius X in 1904. Yet the coding task was not the work of a closed group of experts, but rather it considered the bishops' views, and it was consulted in two different moments; both of which considered the consultation to Chilean bishops. This article studies the contributions of those Chilean bishops in their first consultation, requested in 1904, related

Abogado. Doctor en Derecho por la Universidad Complutense de Madrid y Doctor en Derecho Canónico por la Pontificia Universidad Santo Tomás, Angelicum, de Roma. Profesor titular en la Facultad de Derecho de la Pontificia Universidad Católica de Valparaíso. Miembro ordinario del Pontificio Comité de Ciencias Históricas de la Ciudad del Vaticano. Correo electrónico: csalinas@ucv.cl. Este trabajo forma parte del proyecto de investigación Fondecyt 1070434 del que el autor es investigador responsable.

Fecha de recepción: 21 de octubre de 2008.

Fecha de aceptación: 27 de abril de 2009.

- Abreviaturas: ASS. = Acta Sancta Sedis; ASV. CIC 1917 = Archivo Secreto Vaticano, Fondo Codificación del derecho canónico de 1917; BEAS. = Boletín Eclesiástico del Arzobispado de Santiago; m.p. = motu proprio CIC 1917 = Código de Derecho Canónico de 1917; CIC 1983 = Código de Derecho Canónico de 1983. 
to juristic persons. For this purpose it considers the revision of documents filed in the Secret Vatican File.

KEY WORDS: Canon coding - Code of Canon Law of 1917 - chilean bishops - postulata episcoporum - juristic person - artificial person

SUMARIO: 1) La primera codificación del derecho canónico. 1.1) La necesidad de fijar el derecho canónico. 1.2) La codificación del derecho canónico de 1917. 1.3) Los obispos de la provincia eclesiástica chilena. 1.4) Colaboradores. 2) La persona jurídica. 2.1) El aporte del derecho canónico. 2.2) La persona juridica civil. 3) El aporte de los obispos chilenos. 3.1) El indice de materias. 3.2) La propuesta de los obispos chilenos. 3.3) El Código de Derecho Canónico de 1917. 3.3.1) Definir la personalidad eclesiástica y sus efectos. 3.3.2) Enumerar los institutos, corporaciones y sociedades que debian gozar de personalidad por derecho. 3.3.3) Indicar la autoridad que tenía la facultad de conceder personalidad jurídica a los institutos, a las corporaciones o sociedades que no gocen de la misma por derecho. 3.3.4) Determinar cuáles debian ser los derechos de estas personas, qué facultades, qué cargos serian los propios y peculiares de estas personas y de sus representantes $y$, en general, el régimen de éstas. 3.3.5) Indicar el modo por el cual estas personas se extinguirian y lo que debia hacerse cuando sus constituciones nada dispusieren acerca de los bienes al producirse su extinción. Conclusiones. Bibliografía.

\section{1) LA PRIMERA CODIFICACIÓN DEL DERECHO CANÓNICO}

\section{(1.1) LA NECESIDAD DE FIJAR EL DERECHO CANÓNICO}

El derecho canónico, esto es, el derecho de la Iglesia Católica, constituye un elemento esencial de la misma, razón por la cual las normas en la Iglesia han existido desde los primeros momentos de su historia en una evolución que ya alcanza los dos mil años. Durante el primer milenio dichas normas se recogieron en colecciones canónicas, de diversa naturaleza y contenido ${ }^{1}$, que fueron sustituidas en el segundo milenio por el Corpus Iuris Canonici, un amplio texto integrado por cinco colecciones, la primera de las cuales fue el Decreto de Graciano (1140) seguido por las Decretales de Gregorio IX (1234), el más importante de los textos canónicos

Para una historia del derecho canónico en el primer milenio puede verse GARCía Y GARCía, Antonio (1967). Historia del derecho canónico, I: El primer milenio. Salamanca: Instituto de Historia de la Teología espańola, con abundante bibliografía hasta la fecha de su edición. Más recientemente, con la bibliografía posterior, Edwin Ferme, Brian (1998). Introduzione alla storia delle fonti del diritto canonico, I: Il diritto antico fino al Decretum di Graciano. Roma: Pontificia Università Lateranense. 
de dicho Corpus. Lo integraban, además, el Liber sextus de Bonifacio VIII (1298); las Clementinas, una colección ordenada por el papa Clemente V y promulgada en 1317 por su sucesor, Juan XXII; las Extravagantes comunes y las Extravagantes de Juan XXII, colecciones menores elaboradas en el siglo XVI por el jurista parisino Jean Chapius ${ }^{2}$.

En la medida que fue pasando el tiempo, junto al Corpus se fue elaborando una abundante legislación complementaria que venía a satisfacer las necesidades que iban originando las nuevas realidades históricas que la Iglesia debía enfrentar, de manera que, en pleno siglo XIX, el conocimiento del derecho de la Iglesia se hacía en extremo difícil, con la consecuente dificultad en su aplicación y la secuela de inobservancia que un tal fenómeno trae consigo. Un postulatum de once obispos franceses durante el Concilio Vaticano I (1869-1870) resulta en este sentido revelador ${ }^{3}$ : "Es una cosa muy evidente y reconocida desde hace mucho tiempo por todos y por todas partes reclamada que es necesario y muy urgente un examen y una refundición del derecho canónico. Porque, como consecuencia de los grandes y numerosos cambios sobrevenidos en las circunstancias y en la sociedad humana, muchas leyes han llegado a ser inútiles o inaplicables o muy difíciles de observar. Se duda, incluso, si numerosos cánones se encuentran aún en vigencia. En fin, a lo largo de tantos siglos el número de leyes eclesiásticas ha crecido de tal manera y ellas forman un tal cúmulo de colecciones que, en cierto sentido, podemos decir que estamos aplastados por las leyes. A consecuencia de esto el estudio del derecho canónico está lleno de dificultades inextricables y casi infinitas; el más vasto campo está abierto a las controversias y procesos; las conciencias están oprimidas por miles de angustias y empujadas al menosprecio de la ley". No fueron los únicos, pues otros obispos se manifestaron en el mismo sentido ${ }^{4} \mathrm{y}$, si bien las soluciones que sugerían no fueron coincidentes, algunas de ellas se situaban en la línea de la codificación del derecho canónico ${ }^{5}$, es decir,

2 El Corpus Iuris Canonici fue objeto de una edición oficial a cargo de una comisión romana cuyos miembros fueron llamados 'correctores romanos'. Fue instituida por san Pío V (15661572) y la edición de los correctores romanos publicada por Gregorio XIII (1572-1585) en 1582. Esta edición no recoge la denominación de Corpus Iuris Canonici, la que sí aparece en la edición de Lyon de 1671 y en las posteriores. La edición hoy utilizada habitualmente es la de A. E. Friedberg $(1879,1959)$, Lipsiae. Con posterioridad el Corpus fue complementado incorporándose en diversas épocas otros elementos, algunos de los cuales solo en ediciones privadas.

3 Mansi, J. D. (1903). Sacrorum conciliorum nova et amplissima collectio, Sacrosancti oecumenici Concilii Vaticani: 53, col. 341-342.

4 Además de la intervención señalada en la nota anterior, fueron los postulados suscritos por 37 obispos napolitanos, MANsi, J. D. (1903), col. 378-456, 449-450; 15 obispos alemanes, Mansi, J. D. (1903), col. 352-378, 355; el episcopado belga, Mansi, J. D. (1903), col. 456-461, 460-461; 33 padres de diversas naciones, Mansi, J. D. (1903), col. 478-479; los obispos de las provincias eclesiásticas de Québec y Halifax, MansI, J. D. (1903), col, 467; y un grupo de prelados de Italia central, Mansi, J. D. (1903), col. 552-553.

5 En relación con el debate antecedente a la codificación canónica, puede consultarse: Anó- 
aplicar al derecho de la Iglesia la nueva modalidad de fijar el derecho que se había desarrollado en el derecho de los Estados a partir del siglo XVII, la codificación iusracionalista ${ }^{6}$ que, cuando este debate ocurría en el seno del derecho canónico, ya se había materializado en numerosos códigos, incluso en nuestra patria ${ }^{7}$.

\section{(1.1.2) La codificación del derecho canónico de 1917}

La tarea de elaborar un Codex Iuris Canonici que sustituyera al Corpus fue iniciada por el papa san Pío X (1903-1914) a poco de haber iniciado su pontificado en los albores del siglo XX. Lo hizo mediante el motu proprio Arduum sane munus, de 19 de marzo de $1904^{8}$, mediante el cual creó una comisión pontificia encargada de asumir la codificación del derecho de la Iglesia?

NIMO (1904). "Pio X e la codificazione del diritto canonico". Il contencioso ecclesiastico Vol. 5, pp. 66-68; Bersani, F. (1917). "Le fonti del diritto canonico prima della codificazione". Rivista di diritto eclesiástico, Vol. 10, pp. 23-41; Boudinhon, A. (1904, 1905). "De la codification du droit canonique". Le canoniste contemporain, Vol. 27, pp. 641-650; Vol. 28, pp. 18-23, 76-83, 139-149, 207-215, 302-309, 473-481, 563-568; Calisse, C. (1904). "La codificazione del diritto canonico". Rivista internazionale di scienze sociali, Vol. 35, pp. $346-$ 365; Lamer, H. (1899). Zur Codification des canonischen Rechts. Freiburg: Br., pp. 63-96; 212-213; Ruffini, Francesco (1905). "La codificazione del diritto eclesiástico". En AA. VV., Studi di diritto in onore di Vittorio Scialoja. Milano: II, pp. 353-391; Villien, A. (1906, 1907, 1908). "Les reformes du droit canonique et les postulata du concile du Vaticain". Le canoniste contemporaine Vol. 29, pp. 65-74, 209-221, 369-384, 449-463, 554-564, 652659, 712-717; Vol. 30, pp. 74-83, 137-147, 220-228, 273-283; Vol. 31, pp. 16-23, $207-$ 219, 364-376.

6 Una reciente y completa síntesis sobre la codificación en GuzMán Brito, Alejandro (2007). "El origen y desarrollo de la idea de codificación del derecho". En Guzmán Brito, Alejandro (ed.), El Código Civil de Chile (1855-2005). Trabajos expuestos en el Congreso internacional celebrado para conmemorar su promulgación, Santiago de Chile, 3-6 de octubre de 2005. Santiago: LexisNexis, pp. 43-99.

7 Sobre la codificación del derecho civil en Chile se puede ver, por todos, GuzMán Brito, Alejandro (1982). Andrés Bello codificador. Historia de la fijación y codificación del derecho civil en Chile. Santiago: Ediciones de la Universidad de Chile, 2 vols. Para la codificación civil en Hispanoamérica el más completo y actual trabajo es el de Guzmán Brito, Alejandro (2000). La codificación civil en Iberoamérica. Siglos XIX y XX. Santiago: Editorial Jurídica de Chile, del que hay una segunda edición notablemente ampliada (2006). Cizur Menor, Navarra: Thomson, Aranzadi, The Global Law Colection.

8 Publicado en ASS. Vol. 36, 1903-1904, pp. 549-551. El m.p. lleva la fecha 14 de abril de 1904, pero parece que se trata de un error de imprenta, pues en la carta circular Pergratum mihi, fechada el 25 de marzo de 1904, hay una referencia expresa al m.p. Arduum sane munus. Son de esta opinión, Llobell, Joaquín; De León, Enrique; Navarrete, Jesús (1999). Il libro "De processibus" nella codificazione del 1917. Studi e documenti. Milano: Giuffré, Vol. I, p. 34 n. 30. Sobre los inicios de la codificación piobenedictina puede verse FANTAPPIÈ, Carlo (2002). "Gl'inizi della codificazione pio-benedettina". Il diritto ecclesiastico, Vol, 113, pp. 16-83. Del mismo autor puede verse su libro más reciente (2008) Chiesa romana e modernità giuridica. L'edificazione del sistema canonistico (1563-1903). Milano: Giuffrè, Per la storia del pensiero giuridico moderno, Vol. 76, 2 tomos, con bibliografía actualizada. La nómina de sus integrantes en ASS. Vol, 36, 1903-1904, p. 551. 
La elaboración del código, sin embargo, no fue una tarea de un grupo cerrado de iniciados, sino que, contando con el trabajo de un número importante de expertos bajo la dirección de Pedro Gasparri ${ }^{10}$, el mismo motu proprio dispuso la intervención de todo el episcopado latino ${ }^{11}$. De esta manera, una de las principales características del proceso de codificación del derecho canónico de 1917 consistió en la participación, promovida por la misma Santa Sede, del episcopado en la elaboración del Codex. Dicha participación, por cierto, la primera realizada históricamente por la Iglesia al emprender la tarea de elaborar un cuerpo legislativo universal, se articuló en dos grandes momentos: el primero, al inicio de los trabajos de codificación, a través de los Postulata episcoporum; el segundo, en pleno proceso codificador, cuando se estaba llegando a la fase conclusiva de la misma, a través de las Animadversiones episcoporum. De ambos momentos es el primero el que ahora me interesa.

La primera de las consultas fue llevada a la práctica mediante la circular Pergratum mihi, de la Secretaría de Estado, de fecha 25 de marzo de 1904, enviada a todos los metropolitanos ${ }^{12}$. En ella se disponía que los arzobispos, después de haber oído a sus sufragáneos y otros ordinarios que debían estar presentes en el concilio provincial, debían hacer llegar a la Santa Sede, dentro de los cuatro meses siguientes, en pocas palabras, las principales modificaciones y correcciones que debían hacerse al derecho canónico en vigor. En la misma circular se indicaba que era deseo formal del Papa ver a todo el episcopado concurrir y tomar parte activa en un asunto que interesaba en grado máximo el bien y utilidad de toda la Iglesia Católica ${ }^{13}$.

En la misma circular se comunicaba a los obispos que, por decisión del Santo Padre, los obispos de cada nación tenían la facultad de escoger y enviar a Roma, a su costo, uno o dos especialistas en derecho canónico o teología, que pudiesen formar parte del grupo de consultores; si preferían

10 Antiguo profesor en el Instituto Católico de París, entonces arzobispo titular de Cesarea y secretario de la S. Congregación de asuntos eclesiásticos extraordinarios, a quien se le nombró al mismo tiempo presidente de la Comisión de consultores. Posteriormente sería hecho cardenal (1907).

En la decisión cuarta el Papa manifestaba su deseo de que todo el episcopado, conformándose a las reglas que serían dadas en tiempo oportuno, colaboraran y concurrieran a esta obra tan importante: "IV. Volumus autem universum episcopatum, iuxta normas opportune tradendas, in gravissimum hoc opus conspirare atque concurrere".

12 ASS, Vol. 36, 1903-1904, pp. 603-604.

13 Como se ha observado, se solicitó la colaboración del episcopado para que los consultores, con frecuencia hombres más bien teóricos, fuesen iluminados por las condiciones de vida particular en los diferentes países; la consulta era necesaria para asegurar que el nuevo código tuviese un carácter eminentemente práctico y para que, gracias a las sugerencias de los obispos, se eliminasen todas las imperfecciones del derecho vigente, introduciéndole al mismo tiempo las reformas necesarias. Vetulani, A. (1942). "Codex Juris Canonici". Dictionnaire de Droit Canonique. Paris: Vol. III, col. 920. 
escoger uno de los que ya habían sido nombrados consultores por los cardenales, podían encargarles que los representara para someter a discusión y defender sus proposiciones en las reuniones de los consultores; incluso, podían nombrar a alguno de su nación que, residiendo fuera de Roma, pudiese, por correspondencia, aportar de alguna manera a los consultores el apoyo de su colaboración.

La respuesta de los obispos del mundo latino fue amplia, contándose entre ellas la de numerosos obispos latinoamericanos, incluidos los chilenos. Se calcula en aproximadamente cinco mil el número de personas que fueron consultadas por lo que, no sin razón, se ha dicho que el trabajo de consulta a los obispos fue como un concilio ecuménico por correspondencia.

El numeroso material reunido fue sistematizado según la estructura que se había definido en el índice de materias definido por los cardenales mientras se hacía la consulta, y reproducido en un volumen que permaneció inédito, bajo la dirección del consultor Bernardino Klumper, con el título Postulata Episcoporum in ordine digesta ${ }^{14}$. Posteriormente se agregó un segundo volumen, más breve que el anterior, con solo 68 páginas, impreso en 1908 con el título Appendix ad Postulata Episcoporum, reproducido igualmente por Bernardino $\mathrm{Klumper}^{15}$ en el que se recogen, probablemente, las respuestas llegadas con retraso, cuando el primero de estos volúmenes ya estaba en prensa. Ninguno de los dos volúmenes llegó a empastarse y su circulación quedó estrictamente restringida a los consultores, de manera que no fueron conocidos fuera de ellos. Preciso es tener presente, sin embargo, que no todos los postulata fueron recogidos por Klumper, si bien la mayoría lo fue; pero de estos, el consultor fue recogiendo lo que consideraba de utilidad o cambió de colocación las sugerencias iniciales, por lo que la consulta a los documentos originales se hace indispensable para poder conocer con precisión lo sugerido por los obispos $^{16}$.

Como ha sido puesto de relieve ${ }^{17}$, estos postulata reflejan el sentir del episcopado mundial en lo que se refiere a la codificación y permiten conocer cuales eran las preocupaciones y los problemas que interesaban al episcopado mundial a los inicios del siglo XX, no solo de orden jurídico,

Codex Iuris Canonicil Postulata Episcoporum/ in ordinem digestal al Rmo. P. Bernardino Klumper O. F. M./ Consultorel Romael Typis Vaticanis/ $1905 / 283$ pp. ASV. CIC 1917, scatola 4.

15 ASV. CIC 1917, scatola 6.

16 Al no estar todavía generalizado el uso de la máquina de escribir, la mayoría de los postulata son manuscritos, lo que dificulta su lectura, a lo que hay que agregar el que ellos están escritos en diversas lenguas, porque no todos los obispos usaron el latín para sus respuestas, si bien un número importante usó la lengua oficial de la Iglesia. 
sino también eclesiológico, disciplinar, pastoral, etc.; desde esta perspectiva, los postulata constituyen una útil manera de aproximarse a las realidades de las iglesias locales de la época a partir de unos protagonistas tan directos como son los obispos de cada una de ellas. En ellos se solicitan soluciones que, en no pocos casos, solo fueron adoptadas por el Concilio Vaticano II y el Código de Derecho Canónico de $1983^{18}$.

Concluida la tarea codificadora, el fondo documental originado con ocasión de la misma, y que estaba previsto en el reglamento de la comisión codificadora, permaneció por años en el archivo de la Secretaría de Estado proveniente de la Sagrada Congregación para los asuntos eclesiásticos extraordinarios, que llegó a ser, con el tiempo, la Sección segunda de la Secretaría de Estado, dicasterio del que dependió la comisión codificadora cuando fue creada en 1904. Cuando, en 1963, se inició la revisión del Código de Derecho Canónico de 1917, tarea que dio origen al Código de Derecho Canónico de 1983 en actual vigencia, aquel rico material fue transferido a la Pontificia comisión para la revisión del Código de Derecho Canónico, para que pudiera ser utilizado por esta. Finalizado, a su vez, el trabajo de codificación del Codex de 1983, el fondo documental del Código de 1917 fue enviado al Archivo Secreto Vaticano, integrado por 98 legajos $^{19}$.

Por decisión de Juan Pablo II, el año $1985^{20}$ fue autorizada la consulta de los fondos guardados en el Archivo Secreto Vaticano hasta la conclusión del pontificado de Benedicto XV (1922), decisión que ha permitido acceder a los fondos referidos a la codificación del derecho canónico de 1917 y, por lo mismo conocer la intervención que en ella le cupo a los obispos chilenos ${ }^{21}$. Dichos fondos han de complementarse con el Fondo Doppioni, relativo a la codificación de 1917, consistente en 33 legajos; y con el llamado Fondo CIC-Roberti, también referido a la misma codificación y que consiste en ocho carpetas de documentos diversos. Estos dos últimos se encuentran igualmente en el Archivo Secreto Vaticano. fue dirigida a los rectores de las universidades católicas para pedirles el concurso "en esta empresa importante y dificil'. Circular Perlegisti, en ASS. Vol. 37, 1904-1905, pp. 130-131.

LLOBELL/De León/NaVARRete (1999) 1-3.

AAS. Vol. 78, 1986, p. 378.

Archivo Secreto Vaticano, Commissione (Pontificia) per la codificazione del Diritto Canonico, Índice 1164. Se puede consultar Archivo Secreto Vaticano (2008-2009). Índice de los Fondos y relativos instrumentos de descripción de investigación. Ciudad del Vaticano.
} 


\section{(1.1.3) Los obispos de la provincia eclesiástica chilena}

En marzo de 1904 había en Chile un arzobispado y tres obispados: el arzobispado de Santiago ${ }^{22}$, y los obispados de Concepción ${ }^{23}$, San Carlos de Ancud ${ }^{24}$ y La Serena ${ }^{25}$. Arzobispo de Santiago era Mariano Casanova Casanova (1886-1908); obispo de Concepción era Plácido Labarca Olivares (1890-1905); obispo de San Carlos de Ancud era Ramón Ángel Jara Ruz (1898-1909); y obispo de La Serena era Florencio Fontecilla Sánchez (1890-1909). Tan solo ellos tenían derecho a intervenir en un sínodo provincial y, por lo mismo, solo a ellos era preciso escuchar antes de responder a Roma, tal como estaba señalado en la circular enviada por el secretario de Estado.

De ellos, eran Mariano Casanova y Ramón Ángel Jara quienes tenían una mayor formación y experiencia jurídica. En efecto, el arzobispo Casanova $^{26}$ no solo había recibido una buena formación jurídica que había proyectado como docente ${ }^{27}$, sino que al momento de abordar la respuesta a Roma acumulaba una amplia experiencia como legislador, al llevar adelante

Pío IV (1559-1565) creó el obispado de Santiago el 27 de junio de 1561, por bula Super specula; su texto en Retamal Fuentes, Fernando (1998). Chilensia Pontificia. Monumenta Ecclesiae Chilensia. Santiago: Ediciones Universidad Católica de Chile, Vol. I, Tomo I, pp. 4-9. Gregorio XVI (1831-1846) erigió el arzobispado de Santiago el 23 de junio de 1840, mediante la bula Beneficentissimo divinae providenciae consilio; su texto en RETAMAL (1998) 274-283. La bula está fechada "a los doce días de las calendas de junio" de 1840, día que corresponde al 21 de mayo de ese ańo, aunque, por lo general, se ha indicado como fecha de la bula el 23 de junio de 1840 .

Pío IV creó el obispado de Concepción el 22 de marzo de 1563, mediante la bula Super specula; su texto en Retamal (1998) 34-39.

Gregorio XVI creó el obispado de San Carlos de Ancud el 1 de julio de 1840, mediante la bula Ubi primum. Su texto en Retamal (1999) 294-305.

Gregorio XVI creó el obispado de La Serena el 1 de julio de 1840, mediante la bula Ad apostolicae potestatis fastigium. Su texto en Retamal (1999) 284-293.

26 Araneda Bravo, Fidel (1986). Historia de la Iglesia en Chile. Santiago: Paulinas, pp. $592-$ 620; Araneda Bravo, Fidel (1958). "Mariano Casanova". La Revista Católica, N 981, 1958, pp. 2030-2048; Errázuriz, Crescente (1934). Algo de lo que he visto. Santiago: Nascimento, pp. 351-473; FigueroA, Virgilio (1928). Diccionario histórico biográfico y bibliográfico de Chile 1800-1928. Santiago: Vol. II, pp. 377-378; Larson, Oscar (1928). "Recordando a Mons. Casanova". La Revista Católica. Vol. 54, pp. 660-664; Oviedo Cavada, Carlos (1996). Los obispos de Chile. Santiago: Editorial Andrés Bello, pp. 91-92; Padilla, F. (1958). Monseñor Mariano Casanova, un precursor de los Pactos de Mayo. Córdoba: Impresiones de la Universidad de Córdoba; Prieto del Río, Luis Francisco (1922). Diccionario biográfico del clero secular de Chile 1535-1918. Santiago: Imprenta Chile, pp. 187-189; Retamal Ávila, Julio (1981). Monseñor Mariano Casanova, 1886-1908. Tercer arzobispo de Santiago. Santiago: Editorial Salesiana.

Hizo sus primeros estudios en el Instituto Nacional y posteriormente en el seminario conciliar. En el seminario fue primero inspector y más tarde catedrático de derecho y ciencias eclesiásticas hasta 1868. También fue profesor en el Instituto Nacional, donde desempeñó las cátedras de filosofía y fundamentos de la fe. Se ordenó de sacerdote el 20 de septiembre de 1856, incardinándose en el clero de Santiago. En 1859 fue elegido miembro académico de la Facultad de Teología de la Universidad de Chile; $y$ al ańo siguiente, 1860, se tituló de abogado. 
el Sínodo de Santiago de $1895^{28}$ e impulsar el Concilio Plenario Latinoamericano ${ }^{29}$; y como pastor, al conducir la más importante de las diócesis chilenas. Por su parte, Ramón Ángel Jara ${ }^{30}$ tenía formación jurídica general y canónica en particular, al punto de haberse desempeńado como profesor de derecho canónico en la recién creada Universidad Católica. A ello se agregaba su experiencia episcopal, si bien todavía breve, en cuya calidad había participado con los demás obispos chilenos en el Concilio Plenario Latinoamericano. Su buena formación jurídica se volcaría poco después al celebrar en 1907 el tercer sínodo de Ancud, cuya preparación inició, precisamente, al ańo siguiente de haber respondido la circular de la Santa Sede.

A diferencia de los anteriores, Plácido Labarca ${ }^{31}$, que contaba con 66 ańos al momento de recibirse en Chile la circular del Secretario de Estado, y que moriría al ańo siguiente, no había tenido mayor formación jurídica, salvo la enseñanza general que acerca de los cánones se recibía en el seminario. Tenía, sin embargo, la cercana experiencia del Concilio Plenario Latinoamericano. Y algo similar sucedía con Florencio Fontecilla ${ }^{32}$, si bien cuando en 1904 tuvo que enfrentarse a la circular romana, tenía una amplia experiencia pastoral desarrollada en situaciones difíciles, en la que el derecho canónico debió estar permanentemente presente. Esa sensibilidad por lo jurídico le había llevado a plantear primero y zanjar después para el futuro el tema del juramento civil de los obispos ${ }^{33}$. Y tuvo tam-

28 En 1895 celebró el VII Sínodo de Santiago asamblea que no se realizaba desde 1763, producto del cual fue un texto con 1.888 artículos, que representó el fundamento moral y jurídico de la Iglesia de Chile: Sinodo diocesano celebrado en Santiago de Chile por el Iltmo. y Rmo. Señor arzobispo Dr. D. Mariano Casanova (1896). Santiago: Imp. Roma, $680+119$ pp. Posteriormente fueron publicadas las Fuentes del Sinodo diocesano celebrado en Santiago de Chile por el Illmo. y Rmo. Señor arzobispo Dr. D. Mariano Casanova del 8 al 15 de setiembre de 1895 (1903). Santiago: Imprenta de la Revista Católica, 247 pp.

29. Había propuesto al papa León XIII en 1888 la celebración de un concilio de todos los arzobispos y obispos de la América meridional y fue su principal impulsor. Gaudiano, Pedro (2000). "Presidentes, relatores y miembros del Concilio Plenario de América Latina". En Pontificia Commissio pro America Latina, Los últimos cien años de la evangelización en América Latina. Centenario del Concilio Plenario de América Latina. Actas. Ciudad del Vaticano: Librería Editrice Vaticana, pp. 746-747; CAmus IвACACHe, Misael (1998). "La preparation et la convocation du Concile Plénier d'Amerique Latine célébré à Rome en 1899". Revue d'histoire ecclésiastique, pp. 66-82.

Araneda (1986) 646-651, 680-681; Oviedo (1996) 145-147; Prieto del Río (1922) 343-344.

31 Araneda (1986) 628-629; Figueroa (1928), Vol. III, 609; Oviedo (1996) 148-149; PrieTO DEL Río (1922) 353.

32 Araneda (1986) 640-644; Oviedo (1996) 121-122; Prieto del Río (1922) 252-253.

33 Uno de los primeros problemas que debió abordar al ser nombrado obispo fue el juramento civil de los obispos, que el beato Pío IX (1846-1878) había rechazado por considerar que la fórmula conculcaba los derechos de la Iglesia. El nuevo obispo preguntó al presidente Balmaceda si el juramento civil que debía prestar no estaría reñido con la doctrina y la autoridad de la Iglesia; y al ministro de relaciones exteriores y culto, José Tocornal, le pedía que le aclarara si, a juicio del gobierno, podría el juramento obligarlo a contradecir, en algún caso, la doctrina y la autoridad de la Iglesia. Ambos respondieron entendiendo que el juramento constitucional en ningún caso podría obligar- 
bién la experiencia de participar en el Concilio Plenario Latinoamericano. Con todo, moriría poco tiempo después, en La Serena, el 1 de marzo de 1909, cuando tenía 55 ańos de edad.

\section{(1.1.4) Colaboradores}

Una vez que llegó a manos del arzobispo Casanova la circular Pergratum mibi, de la Secretaría de Estado, de fecha 25 de marzo de 1904, formulando la primera consulta al episcopado latino ${ }^{34}$, el metropolitano nombró una comisión ${ }^{35}$ integrada por cinco sacerdotes que le ayudarían en la elaboración de la respuesta. Ellos fueron: los presbíteros Alberto Vial y Carlos Silva Cotapos, los religiosos fray Raimundo Errázuriz, o.p. y Narciso Sagrega, s.j., todos ellos presididos por el obispo titular de Epifanía, Rafael Fernández Concha. Tarea de la comisión era "que nos ayuden en tan importante asunto, indicándonos los puntos principales que convenga observar".

Rafael Fernández Concha, a petición del Estado de Chile había sido nombrado obispo titular de Epifanía por el papa León XIII, siendo consagrado en Santiago, el 2 de junio de 1901, por Mariano Casanova Casanova, arzobispo de Santiago. Al no tener derecho a participar en el sínodo provincial $^{36}$, no era preciso tomar su parecer, sin embargo, siendo uno de los clérigos más cultos en materias jurídicas ${ }^{37}$, el arzobispo Casanova no

lo a contrariar la doctrina de la Iglesia de manera que, como obispo, no podría obrar en ninguna circunstancia en contra de la ley de Dios o de la autoridad de la Iglesia. Quedaba así claro que el juramento de observar y hacer observar la Constitución de la república no se extendía a aquello que fuese en detrimento de la doctrina o de la autoridad de la Iglesia. Poco después, el cardenal Rampolla, Secretario de Estado de Su Santidad, le contestaba al obispo Fontecilla que "nada resta que hacer al nuevo obispo, sino declarar, cuando sea oportuno, al clero y al pueblo que ba prestado juramento sin perjuicio de las leyes divinas y eclesiásticas".

Decreto de 11 mayo 1904, en BEAS. Vol. 16, 1904-1907, p. 80, n. 129.

Donoso, Justo (1848). Instituciones de derecho canónico americano. Valparaíso: Imprenta El Mercurio, Vol. I, pp. 23-24.

En el Instituto Nacional había sido alumno de Andrés Bello, fue bachiller en humanidades y licenciado en leyes por la Universidad de Chile, en cuya Facultad de leyes enseńó derecho canónico; fue autor de diversos libros jurídicos, filosóficos y religiosos. Tuvo una destacada participación en el sínodo de Santiago de 1895 y en el Concilio Plenario Latinoamericano. Amador Fuenzalida, Enrique (1901). Galeria contemporánea de hombres notables de Chile (1850-1901). Valparaíso, Vol. I, pp. 103-110; Ayala Godox, Hugo (1947). Rafael Fernández Concha. Santiago: Memoria Universidad de Chile; Donoso Espic, Fermín (1962). La filosofia del derecho en Rafael Fernández Concha. Santiago: Editorial Universitaria; JimÉnez B., Julio, s.j. (1962). "En el cincuentenario de don Rafael Fernández Concha". Revista Mensaje $\mathrm{N}^{\circ} 113$, pp. 471-477; "Las bodas de oro del Ilmo. Sr. Obispo de Epifanía, don Rafael Fernández Concha”. La Revista Católica, Vol. 18, 5 febrero 1910, № 205, pp. 80-82; "Necrología. El Ilmo. Obispo de Epifanía, doctor don Rafael Fernández Concha”. La Revista Católica, Vol. 13, 19 octubre 1912, № 269, pp. 757-759; Ossa Busta, Vicente Patricio (1995). "Presbítero Rafael Fernández Concha. Biografia". En Ossa Busta, Vicente Patricio, La capellania ante la jurisprudencia eclesiástica. Casos del arzobispado de Santiago. Santiago: Memoria Universidad de Chile, pp. 3-22; Oviedo (1996) 120-121; Prieto del. Río (1922) 
quiso desaprovechar su colaboración. El mismo, además, por su cuenta, envió un proyecto de cánones preliminares referidos a la constitución de la Iglesia, las leyes y la jurisdicción ${ }^{38}$.

Alberto Vial y Guzmán ${ }^{39}$, del clero de Santiago, después de estudiar en Chile, había estudiado en Roma perfeccionándose en teología, materia que enseñó en el seminario de Santiago a su regreso a Chile, hasta $1902^{40}$. Carlos Silva Cotapos se desempeńaba como secretario del arzobispado cuando fue nombrado por el arzobispo Casanova para integrar la comisión que debía asesorarle en esta primera proposición a Roma, cargo en el que se desempeñaba desde 1902 y en el que permaneció hasta $1914^{41}$. Fray Raimundo Errázuriz Valdivieso había estudiado dos ańos leyes en la Universidad de Chile, ingresando al seminario de Santiago, ordenándose sacerdote el 18 de diciembre de 1863. Algunos años después, en 1869 y 1870 acompañó a su tío, el arzobispo de Santiago Rafael Valentín Valdivieso, al concilio Vaticano I. Entre 1884 y 1911 fue religioso de la Recoleta Dominica, en la que fue varias veces prior. Cuando fue nombrado para incorporarse a esta comisión, era todavía fraile dominico ${ }^{42}$. El último de los colaboradores fue el jesuita Narciso Sagrega.

\section{2) LA PERSONA JURÍDICA}

\section{(2.1) EL APORTE DEL DERECHO CANÓNICO}

Fueron los decretalistas, canonistas del ius commune, los creadores de la persona jurídica moderna a la que, en su última fase, dotaron de una

241-242; Quezada Núnez, Jorge (1995). Juristas chilenos del siglo XIX: Rafael Fernández Concha. Santiago: Memoria Universidad de Chile.

38 Salinas Araneda, Carlos (2007). "Un manuscrito inédito del obispo chileno Rafael Fernández Concha: un proyecto parcial de Código de Derecho Canónico presentado con ocasión de la codificación canónica de 1917". Revista de Estudios Histórico-Jurídicos, №29, pp. 481-514. Prieto del Río (1922) 709-710.

40 En 1887 el arzobispo Casanova lo nombró miembro de la comisión encargada de preparar la fundación de la Universidad Católica en Santiago. Escribía artículos sobre cuestiones religiosas publicados en los diarios católicos del momento, llegando a detentar durante un breve tiempo la dirección del diario El Porvenir. Escribió un libro sobre el clero católico en Alemania -El clero católico en Alemania-, que tuvo tres ediciones -1893, 1894, 1895- y otro sobre la constitución cristiana del Estado a propósito de la encíclica Inmortale Dei, de León XIII -Constitución cristiana del Estado, o sea, declaración de la enciclica Inmortale Dei de la santidad de León Papa XIII de este nombre, Santiago, 1905-. En 1906 publicó Naderias, y en 1910 Estudios religiosos. Falleció en Santiago el 18 de julio de 1918.

41 Posteriormente, además de su labor académica como miembro de la Facultad de Teología de la Universidad de Chile y como historiador, fue nombrado obispo de La Serena (1918-1925) y de Talca (1925-1839), falleciendo el 29 de septiembre de 1941. Oviedo (1996) 215-216.

42 Una vez que obtuvo la secularización, con el nombre de Crescente Errázuriz Valdivieso se incorporó al clero de Santiago, arquidiócesis de la que llegaría a ser arzobispo (1918-1931). Falleció en Santiago el 5 de junio de 1931. Oviedo (1996) 114-115. 
teoría sobre su naturaleza jurídica que, ampliada, daría lugar a la teoría de la ficción. El Derecho romano conoció la existencia de corporaciones con "capacidad de goce", si bien no existió un nombre genérico que las abarcara a todas ellas; quizá los más generales que se encuentren son corpora y universitates; en cambio, especies de corporaciones eran los collegia, sodalitates o sodalicia, lo mismo que civitates, municipia o colonia, siendo el populus Romanus la corporación por excelencia ${ }^{43}$. Con todo, fue extraña a la jurisprudencia romana la idea de que las corporaciones fuesen una persona ${ }^{44}$, como también lo fue la noción de que las corporaciones fuesen personas jurídicas o morales, "como si por sobre la corporación de individuos de que se trata, y además de ella, existiera otro ente que constituyera propiamente una persona" 45 .

El Derecho germánico tampoco aportó un concepto de persona jurídica, si bien trajo una idea fundamental: la idea de nación o de pueblo como unidad que mantiene unos vínculos estrechos, y la noción de sociedad como ente de derecho público y no meramente privado ${ }^{46}$. Esta y la tradición romana confluyeron a partir del siglo XI, conjuntamente con otras circunstancias que obligaron a la ciencia jurídica canónica a plantearse el tema de las entidades que, distintas de las personas o cosas que las componen, son capaces de ser titulares de derechos y obligaciones.

"Si hay que buscar una causa última desencadenante del proceso, únicamente se encuentra en el cristianismo, el cual ofrece el ente de donde parte, y hacia el que confluye, toda la teoría de la personalidad jurídica: la Iglesia" 47 . La Iglesia se presentaba a los ojos del mundo como un ente corporativo que difería de todos los conocidos hasta ese momento: en ella se veía, ciertamente, el elemento humano que se veía en las corporaciones romanas, pues los fieles, el pueblo de Dios, eran su base estructural física. Pero este ente -Iglesia- en sí, esto es la agrupación de todos los fieles entre sí y con Cristo su cabeza, desarrollaba una vida autónoma que no surgía ni solo ni principalmente de las voluntades conjuntadas de los

Guzmán Brito, Alejandro (1997). Derecho privado romano. Santiago: Editorial Jurídica de Chile, Vol. I, p. 418.

44 En D. 46, 1, 22, de Florentino, se lee, respecto de la herencia yacente, que "muerto el reo de prometer se puede recibir fiador aun antes de haber sido adida la herencia, porque la herencia hace las veces de persona, asi como el municipio, la decuria y la sociedad". Aparte el hecho de que la herencia yacente, esto es, la aún no aceptada por el heredero, no es una corporación, el texto no dice que la herencia yacente sea una persona, sino que ella funciona en vez de persona, en el mismo modo como funciona una persona, lo cual implica una analogía pero no una equiparación. Guzmán BrITo, Alejandro (1997) 418. GuZMÁN (1997) 419.

46 Von Gierke, O. (1868, 1954). Das deustsche Genossenschaftsrecht. Berlín: Graz, Vol. I, pp. 12-152, cit. por Bueno Salinas, Santiago (1985). La noción de persona jurídica en el derecho canónico. Su evolución desde Inocencio IV hasta el C.I.C. de 1983. Barcelona: Universitat de Barcelona, Facultat de Teología de Barcelona, Herder, p. 19. 
miembros, sino ante todo de la voluntad inmutable de Dios. No se trataba, pues, de una asociación al modo romano, sino de algo mucho más espiritual y abstracto que tenía su principio rector e informante en una voluntad distinta y superior a la de los miembros ${ }^{48}$.

La idea de corpus atribuida a la Iglesia con un innegable sentido teológico, es oriunda de san Pablo y se encuentra en diversas de sus cartas ${ }^{49}$. Desde una perspectiva teológica, la doctrina paulina plantea el tema de la naturaleza de este Cuerpo, que ciertamente no es física, como tampoco lo es moral o social como puede serlo, por ejemplo, la familia. Se trata, en realidad, de un cuerpo místico: "el divino redentor forma con su cuerpo social una sola persona mística ${ }^{50 "}$. De esta manera, la Iglesia se presenta a los ojos del mundo como un ente corporativo que difiere de todos los hasta entonces conocidos; hay en ella, ciertamente, elementos humanos, una base estructural física, pero la Iglesia en sí realiza una vida autónoma "que no surge ni solo ni principalmente de las voluntades conjuntadas de los miembros, sino ante todo de la voluntad inmutable de Dios. No se trata propiamente hablando de una asociación, y desde luego no lo es al modo típico romano, sino de algo mucho más espiritual y abstracto, que tiene su principio rector e informante en una voluntad distinta y superior de los miembros" 51 . Esta manera de ser original y novedosa no solo no pasó desapercibida, sino que estaba llamada a ser reconocida primero, e influir en el derecho después, como de hecho sucedió. Se trató, por cierto, de un proceso lento.

Panizo Orallo, Santiago (1975). Persona jurídica y ficción. Estudio de la obra de Sinibaldo de Fieschi (Inocencio IV). Pamplona: Eunsa, p. 112.

49 Los textos paulinos más importantes son los siguientes: "asi también nosotros, siendo muchos, no formamos más que un solo cuerpo en Cristo, siendo cada uno por su parte los unos miembros de los otros" (Rm 12, 5); "Porque aun siendo muchos, un solo pan y un solo cuerpo somos, pues todos participamos de un solo pan" (1 Co 10,17); "Pues del mismo modo que el cuerpo es uno, aunque tiene muchos miembros, y todos los miembros del cuerpo, no obstante su pluralidad, no forman más que un solo cuerpo, asi también Cristo. Porque en un solo Espiritu hemos sido todos bautizados, para no formar más que un cuerpo, judios y griegos, esclavos y libres. $Y$ todos hemos bebido de un solo Espiritu" (1 Co 12, 12-13); "Bajo sus pies sometió todas las cosas y le constituyó Cabeza suprema de la Iglesia, que es su Cuerpo, la Plenitud del que lo llena todo en todo" (Ef 1, 22-23); "soportándoos unos a otros por amor, poniendo empeño en conservar la unidad del espiritu con el vinculo de la paz. Un solo Cuerpo y un solo Espiritu, como una es la esperanza a que habéis sido llamados" (Ef 4, 3-4); "El mîsmo dio" a unos el ser apóstoles; a otros, profetas; a otros, evangelizadores; a otros, pastores y maestros, para el recto ordenamiento de los santos en orden a las funciones del ministerio, para edificación del Cuerpo de Cristo, hasta que lleguemos todos a la unidad de la fe y del conocimiento pleno del Hijo de Dios, al estado de hombre perfecto, a la madurez de la plenitud de Cristo" (Ef 4, 11-13); "Él [Cristo] es también la Cabeza del Cuerpo, de la Iglesia" (Col 1, 18); "Ahora me alegro por los padecimientos que soporto por vosotros, y completo en mi carne lo que falta a las tribulaciones de Cristo, a favor de su Cuerpo, que es la Iglesia" (Col 1, 24); "Y que la paz de Cristo presida vuestros corazones, pues a ella habéis sido llamados formando un solo Cuerpo" (Col 3,15). Utilizo la Biblia de Jerusalén.

$50 \quad$ Pío XII (1943), encíclica Mystici Corporis, $\mathrm{n}^{\circ} 31$.

51 Panizo (1975) 112. 
En suma, fueron los decretalistas los creadores de la persona jurídica moderna, a la que, en su última fase, dotaron de una teoría sobre su naturaleza jurídica que, ampliada, daría lugar a la teoría de la ficción. Con todo, y aun cuando en este período se encuentren todos los elementos de las personas jurídicas modernas, no hubo un esfuerzo de sistematización de los mismos, tarea que se realizaría tan solo en los siglos XVII y XVIII. La doctrina de Sinibaldo de Fieschi, primero a nivel doctrinal como canonista y después, a nivel jurídico político, como papa Inocencio IV (1234-1254) $)^{52}$, y de los otros canonistas y civilistas medievales que siguieron sus huellas no era hacer una construcción dogmático-jurídica de la institución, propósito, por lo demás, del todo ajeno en su tiempo, sino aportar soluciones prácticas para defender los derechos de entidades colectivas o patrimonios cuyos fines trascendían las posibilidades del hombre individualmente considerado. "Obviamente, al defenderse estos derechos de manera unitaria, como si fueran los de una persona, se estaban sentando las bases de un concepto abstracto, innegablemente antropomórfico" 53 . El derecho canónico, con todo, mientras su punto de referencia fue el Corpus Iuris Canonici, se planteó problemas concretos, relativos a diversas entidades personales o patrimoniales, como las asociaciones, los cabildos eclesiásticos, los beneficios y otras, pero "sin incurrir en los excesos conceptuales de la dogmática jurídica de los civilistas" ${ }^{4}$.

\section{(2.2) LA PERSONA JURÍDICA CIVIL}

La aceptación por parte de los civilistas de la noción de persona jurídica desarrollada por los canonistas, lo que fue obra principalmente de Bartolo de Sassoferrato (1313-1357), había permitido el desarrollo de la institución en el ámbito civil. Samuel Puffendorf (1632-1694), en el siglo XVII, y con él los juristas de la escuela racionalista de derecho natural, introdujo la noción de persona moral para designar los entes colectivos. Esta noción, sin embargo, adquirió tintes más bien apologéticos, pues no se trataba solo de explicar las soluciones legales, sino más bien reclamar, en

Las decretales de Inocencio IV fueron recogidas posteriormente en el Liber Sextus de Bonifacio VIII y el mismo Inocencio IV las comentó en su Apparatus (Comentaria) super libros quinque Decretalium. Francofurti ad Moenum, 1570; r.a. ibid, 1968. En relación con la obra de este importante pontífice jurista se puede ver a BuEno (1985); Panizo (1975); RUFFinI, Francesco (1936). "La classificazione delle persone giuridiche in Sinibaldo dei Fieschi (Innocenzo IV) ed in Federico Carlo Savigny". En Ruffini, Francesco, Scritti giuridici minori. Milano: Giuffré Editore, Vol. II, pp. 3-90; Rota, A. (1956), "Natura giuridica e forme della istituzione nella dottrina di Sinibaldo dei Fieschi (Papa Innocenzo IV)". Archivio Giuridicho Filippo Serafin, $\mathrm{N}^{\circ} 150$, pp. 67-139.

LOMBARDÍA (1984) 141. 
nombre de la razón, derechos frente al absolutismo, para entidades que se consideraban merecedoras de tal protección.

El avance más notable se produjo en el siglo XIX, con la pandectística alemana. De hecho fue Arnold Heise ${ }^{55}$ quien en 1807 utilizó por primera vez la expresión persona juridica, que fue de inmediato adoptada por Savigny (1779-1861) ${ }^{56}$, el más sobresaliente de todos, al punto que su teoría de la ficción, con la que trató de explicar la naturaleza jurídica de las personas jurídicas, ejerció un influjo notable en las codificaciones civiles, siendo el Código Civil de Chile uno de los que recibió el estímulo de sus construcciones. Y en el ambiente intelectual del positivismo jurídico se entendió que es persona jurídica la entidad que ha sido reconocida como tal por el derecho positivo.

La legislación existente en Chile sobre personas jurídicas en la época en que Bello redactaba su Proyecto de Código Civil era un tanto contraria a ellas. En la legislación española regía una ley de Enrique IV de Castilla (1454-1474) que prohibía los gremios; otra de Felipe III (1598-1621) de 25 de mayo de $1600^{57}$ que ordenaba que todas las cofradías, juntas, colegios y cabildos, aunque fuesen para cosas o fines píos, debían ser precedidas de licencia del rey y del prelado eclesiástico, y que sus reuniones debían hacerse en presencia de delegados del rey y del prelado. Y el 25 de junio de 1783 Carlos III (1759-1788) había dispuesto ${ }^{58}$ que todas las cofradías de oficiales y gremios se extinguiesen, debiendo erigirse en montes píos en las cabezas de obispados, o partidos o provincia, a cargo de Juntas de Caridad. Por su parte, en Francia la ley Le Chapelier ${ }^{59}$ había eliminado los cuerpos y comunidades, y el Code Civil guardaba silencio sobre ellas.

Las ideas de Bello sobre las personas jurídicas, como él mismo lo señala en nota al artículo 645 del Proyecto de $1853^{60}$, las obtuvo del tratado de las personas de Pothier ${ }^{61}$ y del Derecho romano de Savigny. Su habilidad

61 Utilizo Oeuvres de Pothier annotées et mises en corrélation avec le Code Civil et la législation actuelle par M. Bugnet (1861). París: Vol. VII.

HeISE, Arnold (1807). Grundriss eines Systems des gemeinen Civilrechts.

Savigny explicaba que la expresión persona juridica expresaba que ella tenía existencia de persona solo en virtud de una finalidad jurídica. En cambio, no utilizaba la noción de persona moral porque en este instituto no entraba para nada una relación de tipo moral; y porque entre los hombres la expresión moral seńala a quienes se oponen a los inmorales, con lo cual el nombre nos situaba en un orden de ideas diverso. Savigny, F. C. (1849). System des heutigen römischen Recht. Berlin, Vol. II, pp. 85-103. Traducción al italiano de Schialoja (1888), Turín: pp. 239-377. Traducción al castellano de Mesia, J. y Poley, M., 2a ed., Madrid, s.d., Vol. II, p. 60.

Se encuentra en Recopilación de Indias, 1, 4, 25.

La ley se encuentra en Novísima Recopilación, 1, 2, 6.

Promulgada durante la Revolución Francesa, el 14 de junio de 1791, estableció la libertad de empresa y proscribió las asociaciones y corporaciones gremiales de todo tipo las que, en el marco del Antiguo Régimen, impedían el libre ejercicio de las profesiones.

La nota dice: "Art. 645. Véase Pothier, Des Persones, t. 7, des Communautés; Savigny, Droit Romain \$\$ 87 hasta 100" 
estuvo, así, en "transformar elementos doctrinarios en un sistema legislativo completo y operante" 62 . La regulación proporcionada por el Código Civil a las personas jurídicas fue una excepción entre los códigos civiles decimonónicos. De hecho, el Código Civil francés no las reguló; y, si bien el Código de Luisiana lo hizo, las normas referidas a ellas fueron escasas en número y referidas solo a algunos aspectos, a diferencia de la completa regulación que sobre las mismas hizo Bello en su código. No es de extrańar, entonces, que los obispos chilenos, que ya habían conocido las bondades de tal regulación, se inspiraran en ellas para sugerir la conveniencia de que el código canónico que se proyectaba contuviere normas sobre ellas.

\section{3) EL APORTE DE LOS OBISPOS CHILENOS}

\section{(3.1) EL ÍNDICE DE MATERIAS DEL FUTURO CODEX}

Mientras los obispos chilenos preparaban sus sugerencias, en Roma se trabajaba en definir la estructura del Index materiarum, esto es, el esquema que definiría las materias que debía incluir el código canónico que se proyectaba ${ }^{63}$. Después de discusiones y de tres proyectos previos, el cuarto y último proyecto fue presentado a la audiencia de cardenales del 26 de junio de 1904 en la que, bajo la presidencia del Papa, fue aprobado definitivamente el Index materiarum Codicis Iuris Canonici ${ }^{64}$.

El segundo de los cinco libros en que estaba distribuido el contenido del Codex estaba dedicado a las personas - De personis- al frente del cual y antes de las tres partes en las que se dividía ${ }^{65}$, estaba contemplada la exis-

Hanish Espíndola, Hugo (1983). Andrés Bello y su obra en Derecho romano. Santiago: Ediciones del Consejo de Rectores de las Universidades Chilenas, p. 380.

63 Los documentos referidos a la subdivisión de la materias que debía incluir el Código pueden consultarse en Llobel/De León/NAVARRete (1999) 291-351.

64 Su texto en Llobel/De León/Navarrete (1999) 341-351. La estructura general del índice dividía las materias en libros, partes, secciones, títulos y capítulos, sin que para todas las materias se utilizaran siempre todas estas subdivisiones. El índice se iniciaba con la fórmula de profesión de fe y se dividía en cinco libros según el siguiente detalle: el libro primero, dedicado a la parte general, estaba dividido en cinco títulos. El libro segundo, referido a las personas, se dividía en tres partes dedicadas cada una, respectivamente, a los clérigos, los religiosos y los laicos. El libro tercero se dedicaba a las cosas, dividiéndose en seis partes referidas a los sacramentos, los lugares y tiempos sagrados, el culto divino, el magisterio eclesiástico, los beneficios eclesiásticos y los bienes temporales. El libro cuarto, referido a los delitos y las penas, estaba dividido en tres partes, a saber, los delitos en general, las penas, y los delitos en particular y sus penas. El libro quinto y final se refería a los juicios y estaba dividido en tres partes; los juicios en general, los juicios no criminales, y los juicios criminales. En suma se asumió en forma oficial que la estructura de los contenidos del código quedaba dada por la ordenación de las instituciones cuyo uso se había popularizado en las exposiciones doctrinales del derecho de la Iglesia después de que Paolo Lancelotti $(† 1590)$ publicara sus Institutiones Iuris Canonici, inspirándose en las Instituciones de Justiniano.

Pars prima: De clericis. Pars secunda: De religiosis. Pars tertia: De laicis. 
tencia de unos cánones preliminares cuyo contenido genérico se explicaba en una nota a pie de página según la cual, en esos cánones preliminares se debía establecer, entre otras materias ${ }^{66}$, de qué modo se constituyen las personas morales en la Iglesia. Era la única referencia que incluía el índice a las personas jurídicas y ella apenas como una ligera indicación en una nota explicativa a pie de página. Una referencia menor, es verdad, pero al menos se hacía.

\section{(3.2) LA PROPUESTA DE LOS OBISPOS CHILENOS}

En su respuesta a la Santa Sede formulando sugerencias para el nuevo Código de Derecho Canónico que se preparaba ${ }^{67}$, los obispos chilenos dedicaron el punto 44 de su respuesta al tema de las personas jurídicas. Consideraban que era completamente conveniente ${ }^{68}$ que el código canónico sancionara los principios y las reglas referidas a la "personalidad jurídica eclesiástica”, entre las que debían abordarse los siguientes aspectos: i) definir la personalidad eclesiástica y sus efectos ${ }^{69}$; ii) enumerar los institutos, corporaciones y sociedades que debían gozar de personalidad por derecho ${ }^{70}$; iii) indicar la autoridad que tenía la facultad de conceder personalidad jurídica a los institutos, a las corporaciones o sociedades que no gocen de la misma por derecho ${ }^{71}$; iv) determinar cuáles debían ser los derechos de estas personas, qué facultades, qué cargos serían los propios y peculiares de estas personas y de sus representantes y, en general, el régimen de éstas ${ }^{72}$; v) indicar el modo por el cual estas personas se extinguirían y lo que debía hacerse cuando sus constituciones nada dispusieren acerca de los bienes al producirse su extinción ${ }^{73}$.

66 Las otras materias a tratarse eran el modo en que se es persona en la lglesia, a qué edad se alcanza la mayoría de edad y se sugería que quizá podían incluirse los principios generales sobre la fuerza y el miedo que no se refirieren a situaciones particulares.

Informatiol Episcopatus Chilensis de rebus/ in Jure Canonico reformandis/ juxta motum proprium SSmi./ Dni. Nostri Pii Papae X, del Ecclesiae legibus in unum redigendis./ El original en ASV. CIC 1917, scatola 96. Una presentación general de este documento en Salinas AraNEDA, Carlos (2008). "El primer aporte de los obispos chilenos a la codificación del derecho canónico de 1917: los postulata episcoporum". Revista de Estudios Histórico-Juridicos, Vol. 30, pp. 317-342.

"Omnino oporteret canonum Codex principa regulas que sanciret ad juridicam ecclesiasticam personalitatem spectantia, in qua quidem re haec convenirent".

"Definire supradictam personalitatem ejusque effectus".

"Enumerare quae Instituta, Sodalitia et Societates juridica personalitate a jure fruantur". El subrayado es del original.

"Indicare quae auctoritas facultate polleat concedendi juridicam personalitatem Institutis, Sodalitius, aut Societatibus, quae ipsam a jure non possident". El subrayado es del original.

"Determinare harum personarum quae sint jura, quaeque facultates, quae munia propria sint et peculiaria harum personarum vices gerentibus, ac generaliter earum regimen".

"Modum indicere quo hac personae extinguuntur, quidque sit faciendum cum earum constitutiones nihil de extinctarum bonis disposuerint". 
Para reforzar esta propuesta, los obispos consideraron que no era superfluo transcribir algunos de los artículos del Código Civil de Chile en los que se regulan aspectos de los que ellos sugerían, artículos que, puesto que el informe estaba escrito en latín, fueron traducidos en la misma lengua: fueron los artículos $545^{74}, 546^{75}, 549^{76}, 551^{77}, 561^{78}$.

Con esta propuesta, los obispos chilenos se hacían eco de la novedad que había introducido el código chileno en materia de persona jurídica, al recoger normas que expresamente se referían a ella y que ofrecían a los obispos material más que suficiente para sugerir que el futuro código canónico contemplara cánones sobre la misma materia, seguros de que, de hacerlo, tendrían en la Iglesia los mismos efectos benéficos que se habían producido en el tráfico jurídico chileno.

La terminología que usaron en todo momento fue la que aparece en el Código Civil y, por lo mismo, los obispos hablaron de persona jurídica y no de persona moral, denominación que era la que más se usaba en sede canónica. De hecho, fue esta última la usada por los consultores Augusto $\mathrm{Sili}^{79}$ y Carlos Lombardi ${ }^{80}$ quienes, en sus votos escritos sobre las personas jurídicas, utilizaron en todo momento la expresión persona moral.

Código Civil, art. 545: [inc. $1^{\circ}$ ] Vocatur persona juridica persona quaedam fictitia, quae sit capax jura exercendi et obligationes civiles contrabendi, quaeque aliam personam sive in judicio sive extra judicium in locum suum sufficere possit. [inc. $2^{\circ}$ ] Personarum judicarum duae sunt species: sodalitia et fundationes, quae Beneficentiae Publicae nomen habent...". No se incluyó el inc. $3^{\circ}$ : "Hay personas juridicas que participan de uno y otro caracter".

Código Civil, art. 546: "Non habentur uti personae juridicae Fundationes seu Sodalitia, quae instituta non fuerunt per legem quamdam aut quae a Summo Reipublicae Praeside, consentiente summo Status Consilio (apud nos Consejo de Estado), haud fuerint approbatae".

Código Civil, art. 549: "[inc. $1^{\circ}$ ] Bonorum omnium, quae pertinent alicui societati, neque tota neque pars aliqua pertinet cuipiam e personis, societatem constituentibus; atque eodem modo sodalitii debita nemini jus tribuunt ipsa repetendi seu in partem seu in totum a quopiam sodalitium constituente, aut in judicis postulandi istius bona. Tantum repeti possunt illa bona, quae sodalitis pertinent. [inc. $2^{\circ}$ ] Attamen sodalitii socii possunt, cum id expresse dicant, sese obligare suarum bonorum sponsione, simul ac sodalitas sese communium bonorum sponsione obligat: et tunc unusquisque a sociis in solidum tenetur ad debita solvenda, si solidarietas expressis verbis statuta fuerit. [inc. $3^{\circ}$ ] Haec tamen sponsionis obligatio ad haeredes haud transit, nisi cum sodalitatis socii eos expresse obligaverint. [inc. $4^{\circ}$ ] Cum aliqua sodalitas legalem existentiam non habuerit ad mentem articuli 546, ejus collective actos omnes et unumquemque e sociis in solidum obligant".

Código Civil, art. 551: "Sodalitates vices suas gerendas conferre possunt in personas illas, quibus hanc potestatem dederunt leges aut societatis statuta, aut, utrisque deficientibus, communis ejusdem societatis sententia".

Código Civil, art. 561: "[inc. $1^{\circ}$ ] Soluta societate, ejusdem bona ea disponentur forma quae ad hoc praescripta fuerit in ipsius societatis constitutionibus, ac, cum hic casus haud praevisus fuerit, ipsorum bonorum Respublica potietur, hac tamen obligatione, ut eis utatur ad fines haud dissimiles ab illis, ad quos constituta fuerint. [inc. $2^{\circ}$ ] Legislatorum Collegio hos fines indicare proprium erit". Se divide en dos incisos este artículo que en el Código Civil es un inciso único.

80 ASV. CIC 1917, scatola 14. 
Fueron los obispos chilenos los únicos en hacer propuestas en torno a las personas jurídicas. En efecto, en el libro en el que Kumpler recogió los postulata episcoporum llegados a Roma en respuesta a la primera consulta ${ }^{81}$, la proposición de los prelados chilenos se sitúa entre los canones praeliminares del Liber secundus, en la que solo se recogen tres sugerencias: la primera, muy breve, de los padres de la provincia de Holanda, pidiendo que se determinare la edad en que se adquiere la mayoría de edad; la segunda la de los obispos chilenos acerca de la persona jurídi$\mathrm{Ca}^{82}$; y la tercera, también de los obispos de Chile, pero solicitando que se dieren normas ciertas sobre el domicilio y el cuasi domicilio. De esta manera, los únicos obispos que mostraron una mayor sensibilidad sobre el tema fueron los chilenos, coincidiendo en esto con la visión que se tenía en Roma de la conveniencia de que el código canónico que se preparaba recogiere normas en las que se regulare el régimen de las personas jurídicas al interior de la Iglesia. Bien puede decirse, en consecuencia, que nos encontramos ante una proyección hasta ahora desconocida del Código Civil, al menos en este momento inicial de la codificación canónica. Pero es claro que, si bien los codificadores romanos habían incluido el tema de las personas jurídicas en el índice del futuro código, la referencia que ellos hacían era solo al modo en que ellas se constituían, por lo que la propuesta de los obispos chilenos aparece mucho más completa.

Podría considerarse también, a propósito de las personas morales, la propuesta de los obispos de la provincia de Besançon (Francia), en la que sugerían una diversidad de códigos en la Iglesia uno de los cuales debía ser un Código de derecho de la administración, en que se regularen los entes jurídicos y las personas morales en la Iglesia, sus derechos, su administración, etc., además de regular las cancillerías papal y episcopales ${ }^{83}$. Pero, si bien se mencionan las personas morales y se sugieren algunos contenidos de la normativa a emprender, se trata de una referencia tan solo incidental hecha a propósito de una propuesta diversa, por lo que la proposición de los obispos chilenos sigue siendo una propuesta única y, en todo caso, más completa.

\footnotetext{
81 Codex (1905) 22.
}

82 Está redactada en los siguientes términos: "Dentar regulae, in quibus: a) definiatur iuridica personalitas ecclesiastica eiusque effectus; b) enumerentur quae Instituta, sodalitia et societates illa personalitate a iure fruantur; c) indicetur quae auctoritas polleat facultate illam personalitatem concedendi institutos, sodalitiis aut societatibus, quae ea non a iure fruuntur; d) determinantur earumdem personarum iura, facultates, munera propria et peculiaria earum personarum vicesgerentibus, ac generaliter earumden regimen; e) indicetur modus quo extinguuntur, ac quid faciendum sit, cum earum constituciones nihil disponunt de extinctarum bonis". Codex (1905) 22. 


\section{(3.3) El Código de Derecho Canónico de 1917}

El código finalmente promulgado en 1917 dedicó alguna mayor atención a las por él llamadas personas morales que la sugerida en el índice de 1904, ocupándose de ellas entre los cánones 99 y 102, situados, como lo definía el índice, entre los cánones preliminares del libro segundo referido a las personas. No solo afirmó su existencia, sino que las dividió entre colegiadas y no colegiadas ${ }^{84}$, definió las exigencias para su constitución ${ }^{85}$, la actuación de las personas morales colegiadas ${ }^{86}$ y la extinción de las mismas $^{87}$; en otros dos cánones trató de los defectos en la actuación jurídica de estas personas, si bien estos cánones se refirieron tanto a las personas morales como a las físicas ${ }^{88}$.

Los escasos cánones dedicados a las personas jurídicas no pudieron recoger todo lo que los obispos chilenos sugerían, inspirados en la mayor atención que a estas personas dedica el Código Civil, pero algunas de sus inquietudes quedaron recogidas.

CIC 1917, canon 99: "En la Iglesia, además de las personas fisicas, hay también personas morales, constituidas por la autoridad pública, las cuales se dividen en personas morales colegiadas y no colegiadas, como iglesias, seminarios, beneficios, etc.".

CIC 1917, canon 100: "\$1. La Iglesia Católica y la Sede Apostólica tienen la condición de persona moral por la misma ordenación divina; las demás personas morales inferiores la adquieren en la Iglesia, ya por prescripción del derecho, ya por concesión especial del Superior eclesiástico competente, dada por decreto formal para un fin religioso o caritativo. \$2. Para constituir una persona moral colegiada se requiere por lo menos tres personas fisicas. $\$ 3$. Las personas morales, sean o no colegiadas, se equiparan a los menores".

CIC 1917, canon 101: " $\$ 1$. Por lo que respecta a los actos de las personas morales colegiadas: $1^{\circ}$ Si expresamente no ha establecido otra cosa el derecho común o el particular, tiene valor jurídico lo que apruebe la mayoría absoluta de los votantes, descontados los votos nulos, o, después de dos escrutinios ineficaces, la mayoria relativa en el tercer escrutinio; si en el tercer escrutinio hubiere empate, lo resolverá el presidente con su voto; si se trata de elecciones y el presidente no quiere resolverlo con su voto, se tendrá por elegido el más antiguo en el orden o en la primera profesión o en la edad. $2^{\circ}$ Mas lo que a todos, como particulares, atañe, debe ser por todos aprobado. $\$ 2$. Tratándose de los actos de las personas morales no colegiadas, se han de observar los estatutos particulares y las normas del derecho común que se refieren a dichas personas".

CIC 1917, canon 102: " $\$ 1$. La persona moral es perpetua, por su naturaleza; se extingue, sin embargo, si es suprimida por la legitima autoridad, o si deja de existir durante cien años. $\$ 2$. Aunque solo quede uno de los miembros de la persona moral colegiada, en él se concentra el derecho de todos".

CIC 1917, canon 103: "\$1. Los actos que una persona, sea fisica o moral, ejecuta forzada por violencia exterior a la que no se puede resistir, se tienen por no ejecutados. $\$ 2$. Los actos ejecutados por miedo grave e injustamente infundido, o por fraude, son válidos, a no ser que el derecho determine otra cosa; pero conforme a los cánones 1684.1689 pueden ser rescindidos por sentencia del juez, a petición de la parte perjudicada, o bien de oficio". Canon 104: "El error hace nulo el acto, si versa sobre lo que constituye la sustancia del acto o recae sobre una condición sine qua non; de lo contrario, el acto es válido, a no ser que el derecho prevenga otra cosa; pero en los contratos el error puede dar lugar a la acción rescisoria conforme a derecho". 


\section{(3.3.1) Definir la personalidad eclesiástica y sus efectos}

Era la primera propuesta concreta hecha en materia de persona jurídica, la que coincidía con el primero de los artículos del Código Civil que abre el título XXXIII del libro primero, referido a las personas jurídicas, según el cual "se llama persona jurídica una persona ficticia, capaz de ejercer derechos y contraer obligaciones civiles, y de ser representada judicial y extrajudicialmente" (art. 545 inc. $1^{\circ}$ ). Y acto seguido las clasificaba en dos especies: corporaciones y fundaciones de beneficencia pública (art. 545 inc. $2^{\circ}$ ). Fueron precisamente estos dos incisos del artículo 545 los primeros que, recogidos del Código Civil, fueron traducidos al latín e incorporados al informe ${ }^{89}$. Implícitamente los obispos sugerían un concepto al transcribir traducido al latín el artículo del Código Civil que las definía. Nada decían, en cambio, en cuanto a sus efectos, limitándose a sugerir el tema general, pero no su contenido, si bien, implícitamente también aportaban contenidos al transcribir traducido el artículo 549 que regula la responsabilidad de la corporación y de sus miembros.

El código canónico no definió lo que era persona jurídica, o persona moral como la denominó, pero en los cánones referidos a ella proporcionó una clasificación cuando en el canon 99, afirmó que "en la Iglesia, además de las personas fisica, hay también personas morales constituidas por la autoridad pública, las cuales se dividen en personas morales colegiadas y no colegiadas, como iglesias, seminarios, beneficios, etc.". Tampoco definió lo que eran las personas morales colegiadas y no colegiadas. En cuanto a sus efectos, se cuidó de afirmar que "las personas morales, sean o no colegidas, se equiparan a los menores" (can. $100 \$ 3$ ), o que para constituir una persona moral colegiada se requerían por lo menos tres personas físicas (can. 100 $\$ 2$ ), o que la personalidad moral era "dada por decreto formal para un fin religioso o caritativo" (can. $100 \$ 1$ i.f.). Puede decirse, en consecuencia, que solo una parte menor de la petición de los obispos chilenos fue respondida y ella solo parcialmente.

Fue preciso esperar el Código de Derecho Canónico de 1983 para encontrar algo parecido a alguna definición en el conjunto de los cánones que, en número superior, dedicó a las personas jurídicas ${ }^{90}$, entre los cuales hay cánones que, sin ser propiamente definiciones, contenían los elementos esenciales para tener una noción de la persona jurídica de que se trata-

90 CIC 1983, Libro I, De las normas generales, Título VI, De las personas físicas y juridicas, Capítulo II, De las personas juridicas, cánones 113-123. 
ba, corporación ${ }^{91}$ o fundación ${ }^{92}$. Además, introdujo una clasificación que no estaba presente en el código piobenedictino, la de las personas jurídicas públicas y privadas ${ }^{93}$, proporcionando un concepto de la primera ${ }^{94}$, en tanto que daba a las segundas un contenido más bien residual ${ }^{95}$.

\section{(3.3.2) Enumerar los institutos, corporaciones y sociedades que de- bían gozar de personalidad por derecho}

Era la segunda propuesta concreta hecha por los prelados chilenos en relación con las personas jurídicas. "Algunos organismos eclesiásticos, dada su importancia en la vida social y configuración jurídica, ha querido la Iglesia que, de existir, nazcan con la personalidad moral, de tal forma que, una vez cumplidas todas las legalidades que se necesitan para su puesta en marcha, la intervención de la autoridad competente da pie al derecho para que les transmita la personalidad moral" 96 .

También en esta materia los obispos chilenos vieron parcialmente satisfecha su propuesta, pues el código abordó el tema, pero no en la misma forma pedida por ellos. Por de pronto, el canon $100 \$ 1$ hizo la afirmación general y solemne de que "la Iglesia católica y la Sede Apostólica tienen la condición de persona moral por la misma ordenación divina". Pero inmediatamente agregó que "las demás personas morales inferiores la adquieren en la Iglesia, ya por prescripción del derecho, ya por concesión especial del Superior eclesiástico competente, dada por decreto formal para un fin religioso o caritativo". Es decir, el código se limitó a enunciar de manera genérica que había en la Iglesia algunas personas que obtenían su personalidad moral por el derecho mismo, pero no las enumeró, salvo la Iglesia Católica y la Santa Sede que eran expresamente mencionadas, las cuales obtenían su personalidad "por la misma ordenación divina".

91

CIC 1983, canon 115: "\$1. La corporación, para cuya constitución se requieren al menos tres personas, es colegial si su actividad es determinada por los miembros, que con o sin igualdad de derechos participan en las decisiones, a tenor del derecho y de los estatutos; en caso contrario, es no colegial".

CIC 1983, canon 115: " $\$ 3$. La persona jurídica patrimonial o fundación autónoma consta de unos bienes o cosas, espirituales o materiales, y es dirigida, segun la norma del derecho y de los estatutos, por una o varias personas fisicas, o por un colegio".

Preciso es tener presente que no se trata, a diferencia del derecho civil, de personas jurídicas de derecho público y de derecho privado.

CIC 1983, canon $116 \$ 1$ : "Son personas juridicas públicas las corporaciones y fundaciones constituidas por la autoridad eclesiástica competente para que, dentro de los limites que se les señalan, cumplan en nombre de la Iglesia, a tenor de las prescripciones del derecho, la misión que se les confia mirando al bien puiblico; las demás personas juridicas son privadas".

Véase la nota anterior, in fine.

Cabreros de Anta, cmf., Marcelino; Alonso Lobo, op., Arturo; Alonso Morán, op., Sabino (1963). Comentarios al Código de Derecho Canónico. Madrid: Biblioteca de Autores Cristianos, Vol. I, p. 350. 
Con todo, en diversos lugares el código se encargó de definir que algunas personas jurídicas concretas obtenían su personalidad moral en virtud del mismo derecho, ya reconociéndolo explícitamente, como sucedía con los cabildos de canónigos (can. 2332) o las iglesias particulares (can. $1495 \$ 2$ ), ya implícitamente cuando proclamaba sus facultades de poseer, como sucedía con los seminarios (can. 1355). De esta manera, si bien el código canónico no incluyó un canon que enumerara las personas jurídicas que obtenían su personalidad por virtud del derecho mismo, hizo un avance de ello al proclamar que, al menos algunas de ellas, adquirían su personalidad jurídica de esa manera.

En este sentido fue más explícito el Código de Derecho Canónico de 1983 que, si bien tampoco contiene un canon general que enumere las personas jurídicas que obtienen su personalidad jurídica en virtud del mismo derecho, en diversos cánones señaló expresamente que algunas entidades en la Iglesia tienen personalidad jurídica pública. Precisamente, la introducción en el código vigente de la distinción entre personas jurídicas públicas y privadas hacía necesaria una mayor claridad respecto de las primeras, cuando obtienen dicha personalidad por el propio derecho. Se pueden mencionar, entre otras, los seminarios legítimamente erigidos (can. $238 \$ 1$ ), las iglesias particulares (can. 373), la provincia eclesiástica (can. $432 \$ 2$ ), las conferencias episcopales legítimamente erigidas (can. $450 \$ 1$ ), las parroquias (can. $515 \$ 3$ ), los institutos de vida consagrada, las provincias y las casas religiosas (can. 634), etc.

\section{(3.3.3) Indicar la autoridad que tenía la facultad de conceder perso- nalidad jurídica a los institutos, a las corporaciones o socie- dades que no gocen de la misma por derecho}

Es la otra petición de los prelados chilenos quienes, complementando la petición anterior, querían ahora que se definiera con claridad cuáles eran las autoridades que en la Iglesia podían conceder la personalidad jurídica mediante el decreto formal de erección. Para las personas jurídicas civiles lo decía el Código Civil en el artículo 546, cuando afirmaba que "no son personas jurídicas las fundaciones o corporaciones que no se hayan establecido en virtud de una ley, o que no hayan sido aprobadas por el Presidente de la República con acuerdo del Consejo de Estado". Era el segundo de los artículos del Código Civil que, traducido al latín, fue incorporado al informe de los obispos chilenos.

La variedad de estas personas morales canónicas era muy grande por lo que no cabía solicitar su enumeración, como lo hacían los obispos en la petición anterior respecto de las personas morales que obtenían su personalidad jurídica por virtud del mismo derecho, pero procedía pedir, al menos, que se expresara con claridad quiénes podían concederles la personalidad jurídica. 
No hubo tampoco en el código promulgado un canon como el pedido por los obispos chilenos; solo hubo enunciados generales en el sentido de la existencia al interior de la Iglesia de personas morales "constituidas por la autoridad pública" (can. 99), o "por concesión especial del superior eclesiástico competente" (can. $100 \$ 1$ ). Es por lo que la doctrina, cuando se refería a esta materia, expresaba que "cuando exigimos el decreto formal de erección concedido por el superior competente, aludimos al Romano Pontífice para toda la Iglesia y sin limitación de ninguna clase, y también a los Ordinarios del lugar respecto de aquellas personas morales cuya erección no ha sido reservada a otros por privilegio pontificio" ${ }^{\prime 7}$. Por lo general, solían gozar de esta facultad los obispos en sus territorios respectivos, si bien la Santa Sede se había reservado para sí el derecho de erección de algunos colegios o institutos privados, como la de los cabildos catedrales y colegiales (can. 392), o las religiones de derecho pontificio (can. $488 \mathrm{n}^{\circ}$ $3)$. También se reservó a algunos superiores religiosos el privilegio de erigir ciertas asociaciones eclesiásticas (can. $686 \$ 2$ ).

El Codex no eludió el tema, pero, al abordarlo, no lo hizo según la propuesta de los obispos chilenos, sino que utilizó una forma más genérica y algo difusa a lo largo de sus cánones. Es por lo que, en esta materia, tampoco la propuesta episcopal fue acogida. De haberlo sido, el tema de las autoridades encargadas de otorgar la personalidad moral habría alcanzado una notable claridad y simplificación. Fue necesario esperar al Código de Derecho Canónico de 1983 para que la petición de los prelados chilenos fuera acogida, cuando los cánones 312 y 322 dispusieron que la autoridad competente para erigir personas jurídicas eran la Santa Sede para las personas jurídicas universales e internaciones; la Conferencia Episcopal, dentro de su territorio, para las personas jurídicas nacionales, es decir, aquellas que por la erección misma miran a ejercer su actividad en toda la nación; y el obispo diocesano, dentro de su propio territorio, para las personas jurídicas diocesanas.

\section{(3.3.4) Determinar cuáles debían ser los derechos de estas personas, qué facultades, qué cargos serían los propios y peculiares de estas personas y de sus representantes y, en general, el régi- men de estas}

Se trataba de una propuesta tan solo indicativa de contenidos, que los obispos solamente enunciaban pero que no desarrollaban; con todo, la sugerencia pretendía obtener una regulación, si no completa del régimen de las personas jurídicas, al menos lo suficientemente amplia como para proporcionar los rasgos que debían entenderse como los fundamentales 
de su actuar. Con ser una sugerencia, sin embargo, algunos aspectos específicos de los que los obispos entendían que debían ser definidos en los cánones pueden ser obtenidos de dos de los cinco artículo del Código Civil que ellos tradujeron al latín e incorporaron al informe enviado a Roma, en concreto, los artículos 549 y 551: el primero establece los límites de la responsabilidad entre la corporación y sus miembros respecto de los derechos y obligaciones; el segundo define quién representa a las corporaciones.

Los escasos cánones dedicados por el Codex a las personas morales difícilmente podían responder en todos sus términos esta sugerencia, pero algo de lo relativo a su actuar quedó regulado, lo que ocurrió con los actos de las personas morales colegiadas, respecto de los cuales el código proporcionó reglas acerca de los escrutinios para alcanzar las decisiones colegiadas, si expresamente no había establecido otra cosa el derecho común o el particular. En estos casos, según el canon $101 \$ 1 \mathrm{n}^{\circ} 1$, tenía valor jurídico "lo que apruebe la mayoría absoluta de los votantes, descontados los votos nulos, o, después de dos escrutinios ineficaces, la mayoría relativa en el tercer escrutinio; si en el tercer escrutinio hubiere empate, lo resolverá el presidente con su voto; si se trata de elecciones y el presidente no quiere resolverlo con su voto, se tendrá por elegido el más antiguo en el orden o en la primera profesión o en la edad". E inmediatamente se encargaba de aclarar que "lo que a todos, como particulares, atañe, debe ser por todos aprobado", recogiendo la famosa regla romana "quod omnes tangit" (can. $\left.101 \$ 1 \mathrm{n}^{\circ} 2\right)^{98}$. Tratándose de los actos de las personas morales no colegiadas, se debían observar los estatutos particulares y las normas del derecho común que se refiriesen a dichas personas (can. $101 \$ 2$ ).

Eran las únicas normas relativas a esta materia contemplada en el código canónico, por lo que una vez más la propuesta de los obispos chilenos quedó de lado, a menos que entendamos satisfecha parte de su propuesta con el canon referido a los escrutinios.

Algo más explícito, pero no mucho más, fue el Código de Derecho Canónico de 1983, que estableció la necesidad de estatutos aprobados por la autoridad competente para que alguna corporación o fundación consiga personalidad jurídica (can. 117), define quiénes son sus representantes (can. 118), y contiene normas sobre actos colegiales, diferenciando las elecciones (can. $119 \mathrm{n}^{\circ} 1$ ) de otros asuntos (can. $119 \mathrm{n}^{\circ} 2$ ), recogiendo también, como lo hacía el código anterior, la norma romana "quod omnes tangit" (can. $119 \mathrm{n}^{\circ} 3$ ). tado del tema”. Revista de Estudios Histórico-Jurídicos, Vol. 27, pp. 163-175. 


\section{(3.3.5) Indicar el modo por el cual estas personas se extinguirían y lo que debía hacerse cuando sus constituciones nada dispusieren acerca de los bienes al producirse su extinción}

Era la última sugerencia chilena, también inspirada en el Código Civil el que, en diversos artículos, se refiere a la disolución de las corporaciones (art. 559), lo que debe hacerse cuando los miembros de la corporación quedan reducidos a un número que no permite cumplir los objetos para que fue instituida (art. 560), y el destino de los bienes con ocasión de la disolución (art. 561), todo lo cual vale igualmente para las fundaciones (art. 563). De estos, el artículo 561 era el último de los cinco preceptos del Código Civil que los obispos habían traducido al latín e incorporado al informe. Los prelados, no sugerían ningún modo particular de extinción de las personas jurídicas ni qué debía hacerse con sus bienes producida la extinción, pero como el Código Civil tenía disposiciones expresas al respecto, algunas de las cuales eran transcritas en el informe, bien pueden entenderse que su sugerencia iba en el sentido que la futura regulación canónica siguiera de cerca a las normas chilenas.

A diferencia de lo sucedido con las sugerencias anteriores, el código piobenedictino se refirió a ambas materias. Lo hizo primeramente en el canon $102 \$ 1$, al afirmar que "la persona moral es perpetua, por su naturaleza" 99 , sin perjuicio de lo cual se extingue "si es suprimida por la legitima autoridad, o si deja de existir durante cien años"100. El mismo canon en su $\$ 2$ se refería a la situación de que solo quedare uno de los miembros de la persona moral colegida, en cuyo caso "en él se concentra el derecho de todos". Se trataba de una materia que también regula el Código Civil, pero el artículo 560 de este no fue incorporado al informe por lo que su solución no fue conocida en Roma ${ }^{101}$.

En cambio, el artículo 561 del código chileno fue traducido e incorporado en la Informatio, por lo que los obispos implícitamente sugerían como solución la postulada por el derecho chileno: "disuelta una corporación, se dispondrá de sus propiedades en la forma que para este caso hubieren

99

Cuando el Codex afirma que la persona moral eclesiásticas es perpetua por su naturaleza, no quiere significar que haya de ser eterna, sino que el autor debe fundarla con la intención de que dure indefinidamente. Cfr. Cabreros/Alonso/Alonso (1963) 352.

100 aprobación de la autoridad que legitimó su existencia. [inc. $2^{\circ}$ ] Pero pueden ser disueltas por ellas, o por disposición de la ley, a pesar de las voluntad de sus miembros, si llegan a comprometer la seguridad o los intereses del estado, o no corresponden al objeto de su institución". Este artículo no fue incluido en el informe episcopal.

La solución del Código Civil es diversa, pues, "si por muerte $u$ otros accidentes quedan reducidos los miembros de una corporación a tan corto número que no puedan ya cumplirse los objetos para que fue instituida, o si faltan todos ellos, y los estatutos no hubieren prevenido el modo de integrarla o renovarla en estos casos, corresponderá a la autoridad que legitimó su existencia dictar la forma en que haya de efectuarse la integración o renovación". 
prescrito sus estatutos; $y$ si en ellos no se hubiere previsto este caso, pertenecerán dichas propiedades al Estado, con la obligación de emplearlas en objetos análogos a los de la institución. Tocará al Cuerpo Legislativo señalarlos". La solución del Codex fue un tanto diversa: "al extinguirse una persona moral eclesiástica, sus bienes pasan a ser de la moral eclesiástica inmediatamente superior". En uno y otro caso los bienes pasaban a una persona jurídica superior, pero, mientras en el Código Civil esa persona jurídica superior era única para todos, el Estado, en el Codex, en atención a la naturaleza misma de la Iglesia, la persona jurídica superior podía ser variada y esa realidad debía ser reconocida. En el código canónico, además, se reconocía que, no obstante la solución establecida, ella dejaba "siempre a salvo las voluntades de los fundadores o donantes, los derechos legitimamente adquiridos y las leyes particulares por las que se regía la persona moral extinguida".

Los dos temas propuestos por los obispos chilenos en esta última parte de sus sugerencias en relación con las personas jurídicas fueron regulados por el Código de Derecho Canónico, por lo que, desde esta perspectiva, hay coincidencia entre unas y otro. Pero los obispos chilenos no hicieron ninguna propuesta directa con una disciplina concreta por lo que las soluciones recogidas en el Codex no coinciden con las del código chileno que los prelados han tenido a la vista. Podría considerarse que es una propuesta indirecta la del artículo 561 del Código Civil, que es traducido al latín e incorporado al informe episcopal, pero tampoco hay una coincidencia entre la disciplina canónica y la civil o, si se quiere, la hay solo parcial, pues en ambos ordenamientos los bienes de una persona jurídica extinguida pasan a una persona jurídica superior, pero que es diversa en uno y en otro.

Los dos temas son igualmente tratados por el Código de Derecho Canónico de 1983, que prácticamente repite la disciplina del código piobenedictino en lo relativo a la perpetuidad de la persona jurídica y su extinción (can. 120) y al destino de sus bienes una vez extinguidas (can. 123), adecuada ahora a la novedosa distinción entre personas jurídicas públicas y privadas. Pero complementa la disciplina anterior agregando un par de cánones referidos a la fusión de personas jurídicas -corporaciones o fundaciones- públicas (can. 121) y a la división de una personas jurídica pública (can. 122).

\section{CONCLUSIONES}

En la primera propuesta de los obispos chilenos a la codificación del derecho canónico de 1917, una de las instituciones que consideraron conveniente incluir en el código que se preparaba fue la persona jurídica. Una síntesis de lo que significó dicha proposición es posible presentarla en las siguientes conclusiones: 
1) Los obispos chilenos fueron invitados por la Santa Sede a formular sus sugerencias con ocasión de la codificación del derecho canónico que en ese mismo tiempo se iniciaba. En su respuesta los prelados chilenos abordaron las más diversas materias que ellos consideraban de interés recoger en un código. Las proposiciones del Episcopado chileno se contienen en un extenso informe escrito en latín, numeradas correlativamente, sin distinguir entre las diversas materias, todas las cuales se refieren a materias que interesan al derecho de la Iglesia y, por lo mismo, el derecho del Estado de Chile poco o nada podía decir.

2) No obstante lo anterior, algunas de las proposiciones de los obispos chilenos tienen su origen en la experiencia jurídica del Estado de Chile. Cuando correspondió a los prelados hacer sugerencias a la empresa que iniciaba la Iglesia de codificar su propio derecho, el derecho de su propia nación ya llevaba algunos ańos de experiencia en el mismo sentido, pues la codificación de su derecho se había iniciado medio siglo antes con la promulgación del Código Civil al que habían seguido otros. La formación jurídica que tenían algunos de los obispos, y la experiencia que la nación había acumulado en los decenios anteriores les permitieron utilizarla y, a partir de ella, formular algunas sugerencias que ellos consideraban útiles para el derecho de la Iglesia.

3) Una de las propuestas de los obispos chilenos arrancada de la experiencia jurídica chilena, fue acerca de las personas jurídicas. Y como el Código Civil chileno las regulaba en detalle, las propuestas episcopales fueron igualmente detalladas, no solo en cuanto a indicar los temas que debía ser regulados, sino traduciendo al latín e incorporando al informe enviado a Roma cinco de los artículos del Código Civil que regulan las personas jurídicas y que los prelados consideraron interesantes de dar a conocer a los codificadores romanos.

4) Los obispos chilenos fueron los únicos en sugerir que el Código de Derecho Canónico que se preparaba incluyera algunos cánones relativos a las personas jurídicas. Esta sugerencia vino a coincidir con el índice que la comisión codificadora preparaba en Roma mientras los obispos chilenos elaboraban su informe, en el que se incluían, si bien incidentalmente, algunos cánones relativos a las personas morales.

5) La sugerencia de los obispos chilenos en torno a las personas jurídicas fue una de las más extensas de todo el informe enviado por ellos a Roma y la única que incorporó el apoyo de otras normas para fundamentar con más detalle las propuestas que se formulaban. En cambio, el número de cánones que el Código de Derecho Canónico dedicó a las personas morales, nombre con el que se refirió a las personas jurídicas, se limitó tan solo a cuatro. Esto hizo que la mayoría 
de los temas sugeridos por los obispos chilenos no fueran asumidos por el código canónico.

6) La terminología usada por los obispos fue la que aparece en el Código Civil, por lo que los obispos hablaron en todo momento de persona jurídica y no de persona moral, denominación que era la que más se usaba en sede canónica.

7) Por lo general, las propuestas chilenas fueron más bien indicativas de las materias que ellos consideraban pertinentes ser tratadas por el código, en vez de sugerir soluciones específicas para regular las mismas. Como los cánones finalmente dedicados a las personas jurídicas en el código promulgado no fueron muchos, varias de dichas indicaciones quedaron solo como sugerencias sin que el código se hiciera eco de ellas; algunas fueron parcialmente tratadas por el Codex y un par de ellas fueron consideradas en el texto codicial final.

8) Hay algunos casos en que los obispos sugieren soluciones concretas, pero lo hacen indirectamente, al incorporar en su informe algunos artículos del Código Civil, debidamente traducidos al latín, que prescriben una disciplina que ellos han considerado lo suficientemente importante como para que los codificadores romanos al menos la conocieran.

9) Hay una sugerencia de contenido que hacen los obispos en la forma indirecta antes indicada, que se refiere a una materia tratada finalmente por el código: la del destino de los bienes de una persona jurídica extinguida. En este caso la coincidencia del código canónico con el civil es solo parcial, pues, si bien en ambos casos los bienes de la persona jurídica extinguida pasan a una persona jurídica superior, según el Código Civil esa persona jurídica superior es una sola para todos, el Estado; en cambio, para el código canónico, esa persona jurídica puede ser variada, porque es la persona jurídica inmediatamente superior de la persona jurídica extinguida; en otras palabras, no es la misma para todos.

10) Parte de los temas que los obispos sugirieron ser tratados en el código con relación a las personas jurídicas fueron tratados ańos después por el Código de Derecho Canónico de 1983. En este hubo una mayor preocupación por estas personas, consecuencia del mayor desarrollo que las mismas habían tenido durante el siglo XX y de la mayor potencialidad que se les quiso dar al distinguir entre personas jurídicas públicas y privadas, ofreciendo nuevas posibilidades de acción a los fieles. Esto exigía un tratamiento más detenido, lo que se hizo dedicándole un capítulo completo en el libro primero, con un mayor número de cánones que el código piobenedictino, lo que permitió la posibilidad de que se abordaran algunas de las materias que, sugeridas por los obispos chilenos en 1904, recién en 1983 fueron recogidas en un texto codicial. 
11) Las propuestas hechas por los obispos chilenos en materia de persona jurídica son expresión de la cultura jurídica -canónica y civil-que tenía el Episcopado y el clero chilenos al comienzo del siglo XX, la que les habilitó para actuar, en igualdad de condiciones, con los demás obispos de la Iglesia con quienes debieron concurrir en esta tarea que involucraba a la Iglesia universal, haciendo que sus sugerencias superaran en número y en calidad las de no pocos episcopados, incluso europeos. Ello es particularmente manifiesto con el tema de las personas jurídicas, pues el Código Civil chileno era el único de los códigos entonces vigentes que había tratado detenidamente este instituto en su articulado.

\section{BIBLIOGRAFÍA}

Archivo Secreto Vaticano. Commissione (Pontificia) per la codificazione del Diritto Canonico, Índice 1164.

Archivo Secreto Vaticano (2008-2009). Indice de los Fondos y relativos instrumentos de descripción de investigación. Ciudad del Vaticano.

Bersani, F. (1917). "Le fonti del diritto canonico prima della codificazione". Rivista di diritto eclesiástico, Vol. 10, pp. 23-41.

Bueno Salinas, Santiago (1985). La noción de persona jurídica en el derecho canónico. Su evolución desde Inocencio IV hasta el C.I.C. de 1983. Barcelona: Universitat de Barcelona, Facultat de Teología de Barcelona, Herder.

Cabreros de Anta, cmf., Marcelino; Alonso Lobo, op., Arturo; Alonso Morán, op., Sabino (1963). Comentarios al Código de Derecho Canónico. Madrid: Biblioteca de Autores Cristianos, Vol. I.

Camus Ibacache, Misael (1998). "La preparation et la convocation du Concile Plénier d'Amerique Latine célébré à Rome en 1899”. Revue d'histoire ecclésiastique, pp. 66-82.

Codex Iuris Canonici. Postulata Episcoporum in ordinem digesta a Rmo. P. Bernardino Klumper O. F. M. Consultore (1905). Romae: Typis Vaticanis.

Donoso, Justo (1848). Instituciones de derecho canónico americano. Valparaíso: Imprenta El Mercurio, Vol. I.

Fantappiè, Carlo (2002). "Gl'inizi Della codificazione pio-benedettina". Il diritto ecclesiastico, Vol. 113, pp. 16-83.

(2008) Chiesa romana e modernità giuridica. L'edificazione del sistema canonistico (1563-1903). Milano: Giuffrè, Per la storia del pensiero giuridico moderno, Vol. 76, 2 tomos.

FigueroA, Virgilio (1928). Diccionario histórico biográfico y bibliográfico de Chile 1800-1928. Santiago de Chile. 
García y García, Antonio (1967). Historia del derecho canónico, I: El primer milenio. Salamanca: Instituto de Historia de la Teología española Gaudiano, Pedro (2000). "Presidentes, relatores y miembros del Concilio Plenario de América Latina". En Pontificia Commissio pro America Latina, Los últimos cien años de la evangelización en América Latina. Centenario del Concilio Plenario de América Latina. Actas. Ciudad del Vaticano: Librería Editrice Vaticana, pp. 746-747.

Hanish Espíndola, Hugo (1983). Andrés Bello y su obra en Derecho romano. Santiago: Ediciones del Consejo de Rectores de las Universidades Chilenas.

Informatio Episcopatus Chilensis de rebus in Jure Canonico reformandis juxta motum proprium SSmi. Dni. Nostri Pii Papae X, de Ecclesiae legibus in unum redigendis. El original en ASV. CIC 1917, scat. 96.

Lombardía, Pedro (1984). Lecciones de derecho canónico. Madrid: Tecnos.

Llobell, Joaquín; de León, Enrique; Navarrete, Jesús (1999). Il libro "De processibus" nella codificazione del 1917. Studi e documenti. Milano: Giuffré, Vol. I.

Mansi, J. D. (1903). Sacrorum conciliorum nova et amplissima collectio, Sacrosancti oecumenici Concilii Vaticani: 53, col. 341-342.

Merello Arecco, Ítalo (2005). "La máxima 'quod omnes tangit'. Una aproximación al estado del tema". Revista de Estudios Histórico-Jurídicos, Vol. 27, pp. 163-175.

Oviedo Cavada, Carlos (1996). Los obispos de Chile. Santiago: Editorial Andrés Bello.

Panizo Orallo, Santiago (1975). Persona jurídica y ficción. Estudio de la obra de Sinibaldo de Fieschi (Inocencio IV). Pamplona: Eunsa.

Pío XII (1943), encíclica Mystici Corporis.

Prieto del Río, Luis Francisco (1922). Diccionario biográfico del clero secular de Chile 1535-1918. Santiago de Chile.

Retamal Fuentes, Fernando (1998). Chilensia Pontificia. Monumenta Ecclesiae Chilensia. Santiago: Ediciones Universidad Católica de Chile, Vol. I, Tomo I,

Rota, A. (1956). "Natura giuridica e forme della istituzione nella dottrina di Sinibaldo dei Fieschi (Papa Innocenzo IV)". Archivio Giuridicho Filippo Serafin, $\mathrm{N}^{\circ} 150$, pp. 67-139.

Ruffini, Francesco (1905). "La codificazione del diritto eclesiástico". En AA. VV., Studi di diritto in onore di Vittorio Scialoja. Milano: II, pp. 353-391.

(1936). "La classificazione delle persone giuridiche in Sinibaldo dei Fieschi (Innocenzo IV) ed in Federico Carlo Savigny". En Ruffini, Francesco, Scritti giuridici minori. Milano: Vol. II, pp. 3-90;

Salinas Araneda, Carlos (2007). "Un manuscrito inédito del obispo chileno Rafael Fernández Concha: un proyecto parcial de Código 
de Derecho Canónico presentado con ocasión de la codificación canónica de 1917". Revista de Estudios histórico-jurídicos Vol. 29, pp. 481-514.

(2008). "El primer aporte de los obispos chilenos a la codificación del derecho canónico de 1917: los postulata episcoporum". Revista de Estudios histórico-jurídicos, Vol. 30, pp. 317-342.

Vetulani, A. (1942). Codex Juris Canonici, en Dictionnaire de Droit Canonique. Paris. 